\title{
The importance of educating postgraduate pediatric physicians about food allergy
}

This article was published in the following Dove Press journal:

Advances in Medical Education and Practice

19 October 2016

Number of times this article has been viewed

\author{
Mehdi Adeli ${ }^{1-3}$ \\ Mohamed A Hendaus ${ }^{1,2}$ \\ Lukman I Abdurrahim' \\ Ahmed H Alhammadi',2 \\ 'Department of Pediatrics, Hamad \\ Medical Corporation, ${ }^{2}$ Department \\ of Clinical Pediatrics, Weill-Cornell \\ Medical College, ${ }^{3}$ Department of \\ Pediatrics, Sidra Medical and Research \\ Center, Doha, Qatar
}

Background: Food allergy is an increasing public health burden, and is considered among the most common chronic noncommunicable diseases in children. Proper diagnosis and management of food allergy by a health care provider is crucial in keeping affected children safe while simultaneously averting unnecessary avoidance.

Objective: The rationale of the study was to estimate the knowledge of pediatric residents and academic general pediatric fellows with regard to food allergies in children.

Methods: A cross-sectional and prospective study was carried out at Hamad Medical Corporation, the only tertiary care, academic and teaching hospital in the State of Qatar. The study took place between January 1, 2015 and September 30, 2015.

Results: Out of the 68 questionnaires distributed, 68 (100\%) were returned by the end of the study. Among the participants, 15 (22\%) were in post-graduate year-1 (PGY-1), $16(23.5 \%)$ in PGY-2, 17 (25\%) in PGY-3, 12 (16\%) in PGY-4, and 8 (12\%) were academic general pediatric fellows. Our trainees answered $60.14 \%$ of knowledge based questions correctly. In the section of treatment and management of food allergy in childhood, 23 (34\%) of respondents' main concern when taking care of a patient with food allergies was making sure the patient is not exposed to food allergen, while $22(33 \%)$ reported no concerns. In the section of treatment and management of food allergy in childhood, 22 (33\%) of participants reported no concerns in taking care of a child with food allergy, while 23 (34\%) of respondents' main concern was making sure the patient is not exposed to food allergen. In the teaching and training section, $56 \%$ of participants stated that they have not received formal education on how to recognize and treat food allergies, while 59\% claimed not being trained on how to administer injectable epinephrine. Furthermore, approximately $60 \%$ of all participants expressed the need of additional information about recognizing and treating food allergies and recommended certification and regulation of food allergy training for all residents.

Conclusion: There is an appreciable lack of knowledge in identifying food allergy and managing anaphylaxis reaction in children, among pediatric residents. Robust efforts should be implemented by attending immunologists to improve the lack of knowledge and improve the trainee's confidence when facing such cases.

Keywords: allergy, attitude, food, knowledge, training, management, residents, survey, diagnosis, Qatar

\section{Introduction}

Food allergy is an increasing public health burden, and is considered among the most common chronic noncommunicable diseases in children. ${ }^{1,2}$ Almost $25 \%$ of individuals residing in the US perceive having food allergy, while in fact only $8 \%$ of children and $4 \%$ of teens and adults have genuine immunoglobulin E-mediated food reactions. ${ }^{3}$ The
Department of Pediatrics, Hama

Medical Corporation, PO Box 3050

Doha, Qatar

Tel +974 44392239

Fax +974 4443 957।

Email madeli@hamad.qa 
Center for Disease Control and Prevention indicates that food allergies among children have augmented from $3.5 \%$ to $4.6 \%$ between 1997 and 2011. ${ }^{4}$ More recent surveys have shown that almost $10 \%$ of preschool children suffer from clinical food allergy. Moreover, in rapidly developing countries, such as China, the prevalence of clinical food allergy is around $7 \%$ in preschoolers. ${ }^{2}$

Food allergy is associated with a range of skin manifestations such as dermatitis, urticaria, eczema, angioedema, and itching. It also presents with gastrointestinal tract changes such as abdominal cramping, nausea, vomiting, and diarrhea. In addition, food allergy manifests with respiratory illnesses, such as asthma and laryngeal edema. ${ }^{5}$ Anaphylactic shock due to food allergy is the most serious outcome and can lead to death if immediate treatment is not administered. ${ }^{6}$ The most common food allergens that affect children are cow's milk, eggs, wheat, soy and peanuts. Meanwhile, tree nuts, fish, lobster, crab, and shrimp cause allergy more commonly among adults. ${ }^{5,7}$ There is no known cure for food allergies; however, absolute avoidance of food allergens and early recognition and management of allergic reactions to food are crucial measures to evade dreadful health consequences. ${ }^{8}$ Speedy administration (within a few minutes of anaphylaxis) of epinephrine is critically important to manage anaphylaxis properly. ${ }^{9}$

Approximately $20 \%$ of children with food allergies have had a reaction from accidentally ingesting food allergens during school hours. ${ }^{10,11}$ Moreover, $25 \%$ of the severe and potentially life-threatening reactions (anaphylaxis) noted in schools occurred in children with no previous diagnosis of food allergy. ${ }^{10,12}$

Proper diagnosis and management of food allergy by a health care provider is crucial in keeping affected children safe while simultaneously averting unnecessary avoidance. ${ }^{13}$ Since primary care providers are usually the first and perhaps the only physicians these children encounter, it is important that they supply parents or caregivers with conceivably lifesaving medications and provide proper education on how to identify and react to allergic reactions. ${ }^{14}$ Studies have shown that pediatricians adhere poorly to food allergy guidelines. This could be due to pediatricians' deficiency of familiarity with the guidelines, and their accuracy concerning their role in managing food allergy. ${ }^{15}$

Given the increasing concern of food allergies and the crucial role of the primary care physician in its diagnosis and management, the rationale of this study was to estimate the knowledge and attitudes of our postgraduate pediatric physicians regarding food allergies.

\section{Methods}

A cross-sectional and prospective study was carried out at Hamad Medical Corporation, the only tertiary care, academic and teaching hospital in the State of Qatar. The study took place between January 1, 2015 and September 30, 2015. A total of 68 postgraduate pediatric physicians were targeted. In all, 68 eligible physicians were included in the study.

A self-administered questionnaire was handed out onsite during working hours to all pediatric residents and academic general pediatric fellows and was returned by the participants to a specified box. Verbal consent was attained prior to administering the questionnaire, and physicians were informed of why the information was being collected and how it would be used. Before distributing the questionnaire, a statement was read to participants briefing them that their participation was voluntary and assured that their answers would remain anonymous and confidential. There was no incentive for physicians to participate, and we did not provide any reminders. Approval for the study was obtained from Hamad Medical Corporation-Ethics Committee (reference no. MRC/0302/2015).

The questionnaire was composed of four sections and a total of 26 items, and its content was based on previous surveys, ${ }^{16-18}$ but customized to fit our system. These sections addressed physicians' knowledge of food allergy as well as treatment, management, teaching, and training in regard to the disease.

The questionnaire was divided as follows:

1. Sociodemographic data: two questions

2. Knowledge: nine questions

3. Treatments and management: two questions

4. Teaching and training: 12 questions

At the end of the questionnaire, we provided an empty space for any comments.

The answers to questions asked to physicians were of multiple-choice type: "yes", "no", "not sure"; "true", "false", "not sure", and a 5-point Likert scale, ranging from "very uncomfortable" to "very comfortable".

We used descriptive statistics as well as percentages to summarize demographics and all other items. All statistical analyses were done using statistical package SPSS, version 19.0 (IBM Corporation, Armonk, NY, USA).

\section{Results}

All the $68(100 \%)$ questionnaires distributed were returned by the end of the study. The ratio of female to male was 1.5:1. Among the participants, $15(22 \%)$ were in postgraduate year 
(PGY) 1, 16 (23.5\%) in PGY-2, 17 (25\%) in PGY-3, 12 (18\%) in PGY-4, and eight (12\%) were general pediatric fellows.

Our trainees answered $60.14 \%$ of knowledge-based questions correctly. Variation in food allergy knowledge was noticed in each content field (Figures 1 and 2).

In the section on treatment and management of food allergy in childhood (Figure 3), 22 (33\%) participants reported no concerns in taking care of a child with food allergy, while 23 (34\%) respondents' main concern was making sure that the patient is not exposed to the food allergen. Moreover, when asked what other additional restrictions are required in a child with food allergy, one half of participants answered reading labels, followed by "nothing" (18\%), measles/mumps/rubella and influenza vaccines for egg allergy (16\%), healthy food (7\%), vegetarian diet (7\%), and low fat $(6 \%)$.

In the teaching and training section, $56 \%$ of participants stated that they have not received formal education on how to recognize and treat food allergies, while $59 \%$ claimed not being trained on how to administer injectable epinephrine. In addition, only $43 \%$ of the trainees stated that they have witnessed food allergy emergency during their pediatric residency training. Furthermore, approximately $60 \%$ of all participants expressed the need of additional information about recognizing and treating food allergies and recommended certification and regulation of food allergy training for all residents. Participants were also asked to list the main topics in food allergies needed to be mastered. Sixty percent of trainees required more information regarding epinephrine auto-injector administration, followed by $50 \%$ requesting information of how to counsel parents about food allergy, and $45 \%$ wanted more literature on how to recognize signs and symptoms of food allergy and anaphylaxis. Answers to

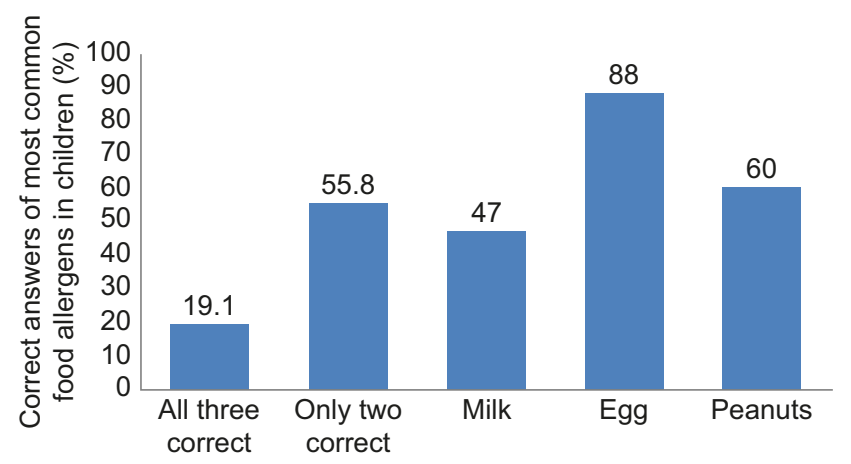

Figure I Physicians were asked which of the following are the three most common food allergens in children.

questions related to the comfort level in dealing with patients who have food allergy were well distributed across a fivepoint Likert scale, ranging from very uncomfortable to very comfortable (Table 1).

Finally, there was no statistical significance $(P>0.05)$ of correct answers in the sections related to knowledge, management, and teaching and training across all levels of pediatric trainees.

\section{Discussion}

Our study has shown that there is a deficiency in knowledge of food allergy as well as treatment, management, teaching, and training in regard to the disease among pediatric physicians in training. This study is the first to supply a comprehensive review of food allergy knowledge and perceptions among pediatric physicians in training in the State of Qatar.

It should be noted that only $5 \%$ of participants felt very comfortable in caring for a patient with a food allergy, while barely $20 \%$ of respondents correctly identified milk, egg, and peanuts as the three most common food allergens in children.

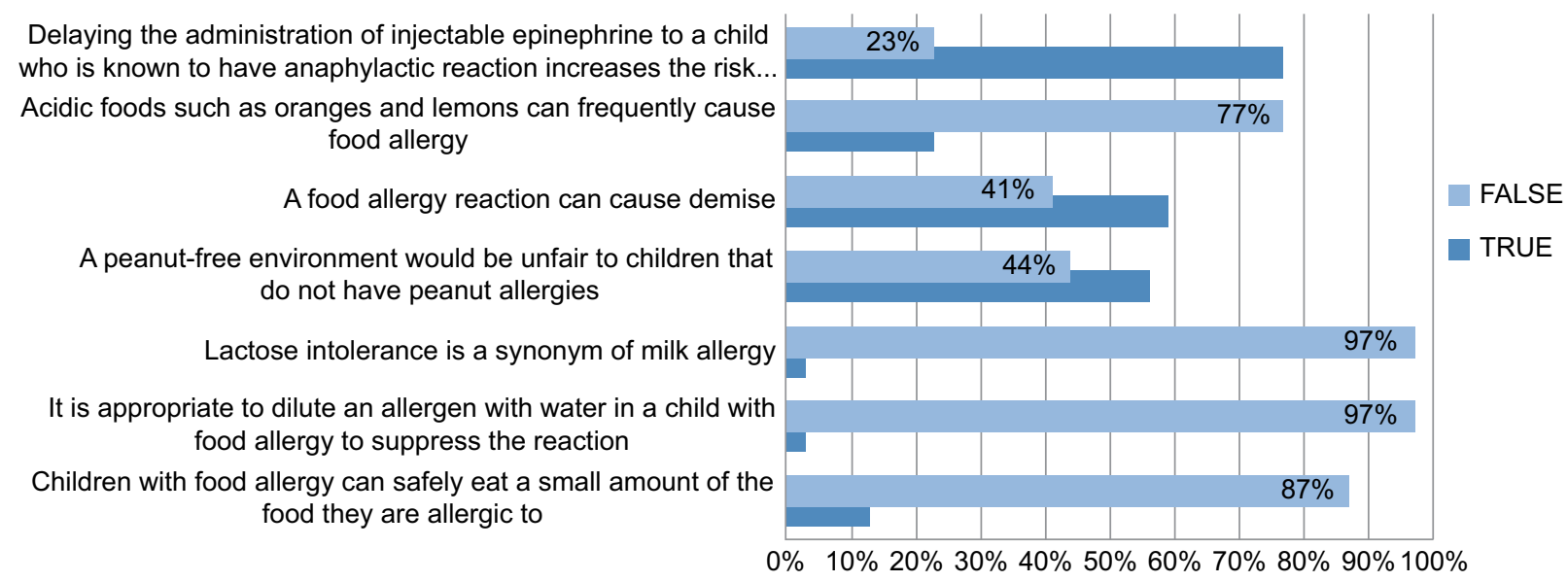

Figure 2 Answers to statements related to knowledge in food allergy. 


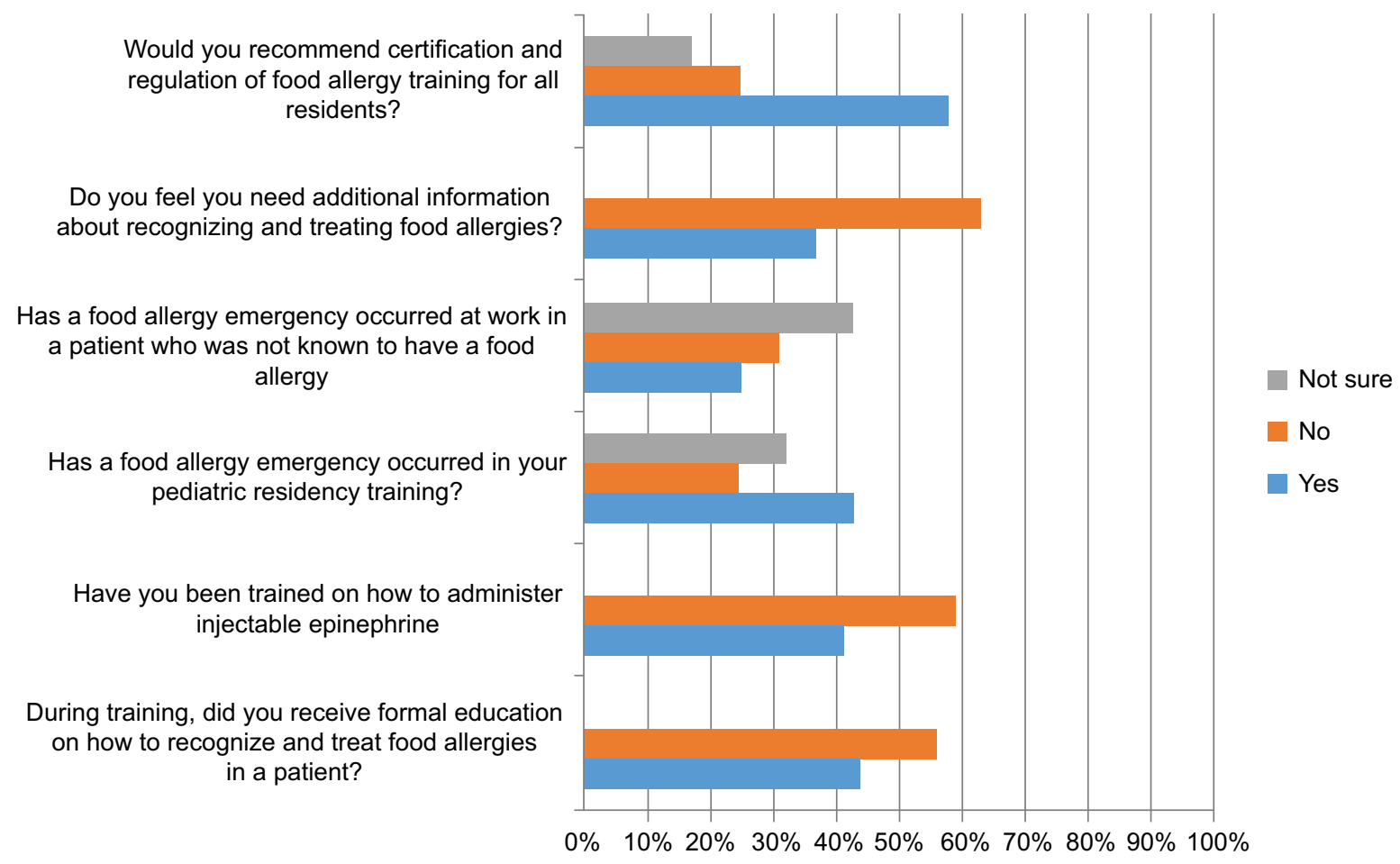

Figure 3 Answers to statements related to teaching and training.

Strikingly, only one in four physicians agreed that food allergy can cause anaphylactic shock and death. However, more than three-quarters of the participants recognized the importance of timely administration of epinephrine.

A few authors have studied perception, knowledge, and management of food allergies among physicians. For instance, a study conducted by Wang et $\mathrm{al}^{19}$ on primary care physicians' approach to food-induced anaphylaxis showed that residents and fellows were more capable of identifying and managing food allergy reactions with adrenaline than attending physicians. A different study conducted by Krugman et $\mathrm{a}^{20}$ has shown that pediatricians were incompletely educated to recognize and treat anaphylaxis due to food allergy. The investigators advised that the decreasing opportunity to choose subspecialty elective rotations during residency was the main culprit in deficiency in knowledge as well as management of anaphylaxis in new graduates. Furthermore, Klemans et $\mathrm{al}^{21}$ investigated the management of food allergic reactions by general practitioners. The study showed that management choice was dependent on the severity of the reaction (mild vs. anaphylaxis, $P<0.001$ ). Nevertheless, epinephrine was used for management of anaphylaxis with predominantly respiratory symptoms in only $27 \%$ of participants and for anaphylaxis with primarily cardiovascular manifestations in $73 \%$.

A study conducted by Gupta et a $1^{18}$ on food allergy knowledge, attitudes, and beliefs in 407 pediatricians and primary care physicians showed that doctors' overall knowledge was average, and fewer than $30 \%$ of the respondents felt comfortable in taking care of children with food allergies.

Physicians usually report lack of proper training in the care of children with food allergy leading to hesitance in managing the disease. ${ }^{22}$ This was echoed by our participants where $60 \%$ of physicians who were surveyed acknowledged the need for more training regarding management of children with food allergies. Through their comments, it is obvious that participants require supplementary educational means and certificates for food allergy training.

Studies have shown that a large proportion of primary care physicians in the US are not supplying patients with the modes to properly manage food-induced reactions. ${ }^{16,22-24}$ Amid the augmentation of prevalence in food allergy and its often serious complications, it is crucial for primary care physicians to be familiarized about this condition. A study conducted by Baptist and Baldwin showed that physicians who rotated under the allergy/immunology services during their training years were more comfortable with common allergic disorders than those who did not select the rotation. ${ }^{25}$

A critical point in our study was that the percentage of correct answers did not improve with higher level of training. Our program despite being located in the Middle East is accredited by the Accreditation Council of Graduate Medical Education-International, and hence, our results could be similar if conducted in the US. 
Table I Answers related to level of comfort in dealing with food allergy cases

\begin{tabular}{|c|c|c|}
\hline Variables & Frequency $(n)$ & Percentage (\%) \\
\hline \multicolumn{3}{|c|}{ Rate your comfort in caring for a patient with food allergy } \\
\hline Very uncomfortable & 2 & 3 \\
\hline Somewhat uncomfortable & 12 & 18.2 \\
\hline Neutral & 34 & 51.5 \\
\hline Somewhat comfortable & 12 & 18.2 \\
\hline Very comfortable & 6 & 9.1 \\
\hline Total $^{\mathrm{a}}$ & 6 & 100 \\
\hline \multicolumn{3}{|c|}{ Rate your comfort in recognizing a food allergy emergency } \\
\hline Very uncomfortable & 4 & 6.3 \\
\hline Somewhat uncomfortable & 9 & 14.1 \\
\hline Neutral & 22 & 34.4 \\
\hline Somewhat comfortable & 21 & 32.8 \\
\hline Very comfortable & 8 & 12.5 \\
\hline Total $^{\mathrm{a}}$ & 64 & 100 \\
\hline \multicolumn{3}{|c|}{ Rate your comfort in treating a food allergy emergency } \\
\hline Very uncomfortable & 3 & 4.6 \\
\hline Somewhat uncomfortable & 10 & 15.4 \\
\hline Neutral & 24 & 36.9 \\
\hline Somewhat comfortable & 22 & 33.8 \\
\hline Very comfortable & 6 & 9.2 \\
\hline Total $^{\mathrm{a}}$ & 65 & 100 \\
\hline \multicolumn{3}{|c|}{$\begin{array}{l}\text { Rate your comfort in suggesting a safe meal for your patients } \\
\text { with food allergies }\end{array}$} \\
\hline Very uncomfortable & 4 & 5.9 \\
\hline Somewhat uncomfortable & 13 & 19.1 \\
\hline Neutral & 26 & 38.2 \\
\hline Somewhat comfortable & 14 & 20.6 \\
\hline Very comfortable & 9 & 13.6 \\
\hline Total $^{\mathrm{a}}$ & 66 & 100 \\
\hline \multicolumn{3}{|c|}{ How comfortable do you feel about giving someone in your } \\
\hline Very uncomfortable & 6 & 9.2 \\
\hline Somewhat uncomfortable & 16 & 24.6 \\
\hline Neutral & 23 & 35.4 \\
\hline Somewhat comfortable & 11 & 16.9 \\
\hline Very comfortable & 9 & 13.8 \\
\hline Total $^{\mathrm{a}}$ & 65 & 100 \\
\hline
\end{tabular}

Note: aSome questions were not answered.

Food allergy education resources have been refined for generalists $;{ }^{26}$ however, work is required to boost the dissemination and use of these resources to better prepare primary care physicians to meet the needs of their food allergic patients. Acquaintance with available resources is the initial step in enhancing physicians' knowledge and confidence in managing food allergy.

Restriction of duty hours was one of the obstacles that we faced when trying to make the allergy/immunology rotation as a core or selective rotation in the residency program. In order to cover the gap in knowledge among trainees, the first author of this manuscript started the Allergy and Immunology Awareness program (AIAP), with a main aim to create educational materials for patients and their families as well as doctors, nurses, and other health care providers related to allergy and immunology. The AIAP has produced around 20 publications in the last 2 years (http://aiap.hamad.qa), two of which were handed to residents and fellows to improve their knowledge of food allergy in children.

One of the strengths of our study is that our results can be implemented in many countries, while a limitation is that our data could have been more appealing if we could have compared the knowledge and attitudes of pediatric trainees before and after an allergy rotation.

\section{Conclusion}

There is an appreciable lack of knowledge in identifying food allergy and managing anaphylaxis reaction in children, among pediatric residents. Pediatric residency working hours' rule impedes the option of having an allergy/immunology rotation during residency. Robust efforts should be implemented by attending immunologists to improve the lack of knowledge and improve the trainee's confidence when facing such cases. This can be accomplished by implementing an allergy/immunology rotation to all pediatric trainees, and by introducing simple food allergy guidelines.

\section{Authors' contributions}

All the authors researched the data, designed the structure, wrote the first draft, critically reviewed the manuscript, and approved the final manuscript as submitted.

\section{Acknowledgment}

The authors would like to thank the Medical Research Center in Hamad Medical Corporation for their support and ethical approval.

\section{Disclosure}

The abstract of this paper was presented at the session 520 at the American Academy of Allergy, Asthma \& Immunology Annual Meeting on March 4-7, 2016, in Los Angeles, CA, with interim findings. The abstract was published in The Journal of Allergy and Clinical Immunology, February 2016, Volume 137, Issue 2, Supplement, page AB159. The authors report no conflicts of interest in this work.

\section{References}

1. Branum AM, Lukacs SL. Food allergy among U.S. children: trends in prevalence and hospitalizations. NCHS Data Brief. 2008;(10):1-8.

2. Prescott SL, Pawankar R, Allen KJ, et al. A global survey of changing patterns of food allergy burden in children. World Allergy Organ J. 2013;6(1):21.

3. American College of Allergy, Asthma, \& Immunology. Food allergy: a practice parameter. Ann Allergy Asthma Immunol. 2006;96(3 Suppl 2): S1-S68. 
4. Centers for Disease Control and Prevention. QuickStats: percentage of children aged $<18$ years with food, skin, or hay fever/respiratory allergies - National Health Interview Survey, United States, 1998-2009. 2011. Available from: www.cdc.gov/mmwr/preview/mmwrhtml/ mm6011a7.htm?s_cid+mm6011a7_w. Accessed October 12, 2015.

5. Taylor SL, Hefle SL. Food allergies and other food sensitivities. Food Technol. 2001;55(9):68-83.

6. Sampson HA, Muñoz-Furlong A, Campbell RL, et al. Second symposium on the definition and management of anaphylaxis: summary report--second National Institute of Allergy and Infectious Disease/Food Allergy and Anaphylaxis Network symposium. Ann Emerg Med. 2006;47(4): 373-380.

7. Ahn K. Food allergy: diagnosis and management. Korean J Asthma Allergy Clin Immunol. 2011;31(3):163-169.

8. Food allergies: What you need to know [webpage on the Internet]. Silver Spring, MD: U.S. Food and Drug Administration; 2016 [updated 24/05/2016]. Available from: http://www.fda.gov/Food/IngredientsPackagingLabeling/FoodAllergens/ucm079311.htm. Accessed October 8, 2016.

9. Joint Task Force on Practice Parameters; American Academy of Allergy, Asthma and Immunology; American College of Allergy, Asthma and Immunology; Joint Council of Allergy, Asthma and Immunology. The diagnosis and management of anaphylaxis: an updated practice parameter. J Allergy Clin Immunol. 2005;115(3 Suppl 2):S483-S523.

10. Sicherer SH, Furlong TJ, DeSimone J, Sampson HA. The US Peanut and Tree Nut Allergy Registry: characteristics of reactions in schools and day care. J Pediatr. 2001;138(4):560-565.

11. Nowak-Wegrzyn A, Conover-Walker MK, Wood RA. Food-allergic reactions in schools and preschools. Arch Pediatr Adolesc Med. 2001;155(7):790-795.

12. McIntyre CL, Sheetz AH, Carroll CR, Young MC. Administration of epinephrine for life-threatening allergic reactions in school settings. Pediatrics. 2005;116(5):1134-1140.

13. Gupta RS, Springston EE, Warrier MR, et al. The prevalence, severity, and distribution of childhood food allergy in the United States. Pediatrics. 2011;128:e9-e17.

14. NIAID-Sponsored Expert Panel; Boyce JA, Assa'ad A, Burks AW, et al. Guidelines for the diagnosis and management of food allergy in the United States: report of the NIAID-Sponsored Expert Panel. J Allergy Clin Immunol. 2010;126(6 Suppl):S1-S58.
15. Gupta RS, Lau CH, Dyer AA, et al. Food allergy diagnosis and management practices among pediatricians. Clin Pediatr (Phila). 2014;53(6):524-530.

16. Cruz NV, Wilson BG, Fiocchi A, Bahna SL; American College of Allergy, Asthma and Immunology Adverse Reactions to Food Committee. Survey of physicians' approach to food allergy, Part 1: prevalence and manifestations. Ann Allergy Asthma Immunol. 2007;99(4):325-333.

17. Greiwe JC, Pazheri F, Schroer B. Nannies' knowledge, attitude, and management of food allergies of children: an online survey. J Allergy Clin Immunol Pract. 2015;3(1):63-67.

18. Gupta RS, Springston EE, Kim JS, et al. Food allergy knowledge, attitudes, and beliefs of primary care physicians. Pediatrics. 2010;125(1):126-132.

19. Wang J, Sicherer SH, Nowak-Wegrzyn A. Primary care physicians' approach to food-induced anaphylaxis: a survey. JAllergy Clin Immunol. 2004;114(3):689-691.

20. Krugman SD, Chiaramonte DR, Matsui EC. Diagnosis and management of food-induced anaphylaxis: a national survey of pediatricians. Pediatrics. 2006;118(3):e554-e560.

21. Klemans RJ, Le TM, Sigurdsson V, et al. Management of acute food allergic reactions by general practitioners. Eur Ann Allergy Clin Immunol. 2013;45(2):43-51.

22. Wilson BG, Cruz NV, Fiocchi A, Bahna SL; American College of Allergy, Asthma \& Immunology Adverse Reactions to Food Committee. Survey of physicians' approach to food allergy. Part 2: allergens, diagnosis, treatment, and prevention. School Nurse News. 2008;25(5): $14-15$.

23. Gupta RS, Springston EE, Smith B, Pongracic J, Holl JL, Warrier MR. Parent report of physician diagnosis in pediatric food allergy. J Allergy Clin Immunol. 2013;131(1):150-156.

24. Sicherer SH, Forman JA, Noone SA. Use assessment of self-administered epinephrine among food-allergic children and pediatricians. Pediatrics. 2000;105(2):359-362.

25. Baptist AP, Baldwin JL. Physician attitudes, opinions, and referral patterns: comparisons of those who have and have not taken an allergy/immunology rotation. Ann Allergy Asthma Immunol. 2004;93(3):227-231.

26. Yu JE, Kumar A, Bruhn C, Teuber SS, Sicherer SH. Development of a food allergy education resource for primary care physicians. BMC Med Educ.2008;8:45.
Advances in Medical Education and Practice

\section{Publish your work in this journal}

Advances in Medical Education and Practice is an international, peerreviewed, open access journal that aims to present and publish research on Medical Education covering medical, dental, nursing and allied health care professional education. The journal covers undergraduate education, postgraduate training and continuing medical education

\section{Dovepress}

including emerging trends and innovative models linking education, research, and health care services. The manuscript management system is completely online and includes a very quick and fair peer-review system. Visit http://www.dovepress.com/testimonials.php to read real quotes from published authors. 